Invited review

\title{
Multiple mechanisms involved in oxytocin-induced modulation of myometrial contractility
}

\author{
Anatoly SHMYGOL ${ }^{1}$, Joanna GULLAM, Andrew BLANKS, Steven THORNTON \\ Clinical Sciences Research Institute, Warwick Medical School, University of Warwick, Coventry, UK
}

\author{
Key words \\ oxytocin; uterus; intracellular calcium; sar- \\ coplasmic reticulum; calcium sensitization \\ ${ }^{1}$ Correspondence to Dr Anatoly SHMYGOL. \\ $\mathrm{Phn}$ 44-0-24-7696-8702. \\ Fax 44-0-24-7696-8653. \\ E-maila.shmygol@warwick.ac.uk \\ Received 2006-05-19 \\ Accepted 2006-05-29 \\ doi: $10.1111 /$ j.1745-7254.2006.00393.x
}

\begin{abstract}
Oxytocin is a small peptide hormone with multiple sites of action in human body. It regulates a large number of reproduction-related processes in all species. Particularly important is its ability to stimulate uterine contractility. This is achieved by multiple mechanisms involving sarcoplasmic reticulum $\mathrm{Ca}^{2+}$ release and sensitization of the contractile apparatus to $\mathrm{Ca}^{2+}$. In this paper, we review the data published by us and other groups on oxytocin-induced modulation of uterine contractility. We conclude that sensitization of contractile apparatus to $\mathrm{Ca}^{2+}$ is the most relevant physiological effect of oxytocin on human myometrium.
\end{abstract}

\section{Oxytocin receptor system and human repro- duction}

Human parturition is a complex sequence of events that concludes in the coordinated processes of cervical dilation and uterine contraction. For most of human pregnancy the myometrium remains relatively quiescent, allowing development of the fetus. Towards the end of pregnancy, there is a relatively gradual change from myometrial quiescence to a more contractile state. The transformation of the uterine muscle from quiescent to contractile was termed "activation" and is thought to involve increased synthesis of contraction-associated proteins ${ }^{[1,2]}$. Activation prepares the uterus for labor and alters it from a relatively insensitive organ to a sensitive, pro-contractile organ. Once the uterus has become activated, a process termed "stimulation" initiates the powerful coordinated contractions of labor. It is accepted that nonapeptide hormone oxytocin has a fundamental role in the stimulation process, and there is growing evidence that this hormone might also contribute to the process of activation as well.

Oxytocin was first extracted from the human posterior pituitary in 1906 by Sir Henry Dale ${ }^{[3]}$. The chemical structure of oxytocin was determined in 1953 by Du Vigneaud et $a l^{[4]}$. Soon after the discovery of its uterotonic activity, the pituitary extract was used for treatment of postpartum hemorrhage $^{[5]}$. Half a century later, obstetricians started using oxytocin for induction of labor ${ }^{[6]}$. In recent years, it has become apparent that oxytocin is involved in a much greater number of reproduction-related processes. Apart from modulating the uterine contractions during parturition, oxytocin is essential for milk ejection during lactation ${ }^{[7]}$. Furthermore, the widespread distribution of oxytocin receptors in the brain and the specific behavioral effects of centrally applied oxytocin point towards its role as a central neurotransmitter mediating reproduction-related processes such as maternal behavior, sexual receptivity and partnership bonding ${ }^{[8]}$. For in-depth discussion on different aspects of oxytocin biology the reader is referred to several detailed reviews published in the last few years ${ }^{[9-13]}$. In the present paper, we will reflect on our own work and the work of other groups on oxytocin-induced modulation of uterine contractility. Because oxytocin is one of the most potent uterotonic agents known, its effect on uterine contractility is of major pharmacological importance. Thus, synthetic analogs of oxytocin are widely used to induce labor and to treat postpartum hemorrhage. Premature activation of the oxytocin system might be a leading cause of preterm labor, therefore the antagonists of oxytocin receptors have been extensively tested as means of inhibiting premature uterine contraction. The effectiveness of atosiban, one of the most potent oxytocin receptor antagonists, has been tested in clinical trials ${ }^{[14,15]}$. Based on these studies, atosiban is currently approved for clinical use in 29 countries. Despite the extensive clinical use of oxytocin and oxytocin receptor inhibitors, the molecular and cellular mechanisms underlying oxytocin-induced 
modulation of uterine contractility are not completely understood. The oxytocin receptor belongs to the G-protein coupled receptor family. After binding oxytocin, the receptor activates phospholipase- $C \beta$ by coupling to $\mathrm{G}_{\mathrm{q}} / \mathrm{G}_{11}$ GTPbinding proteins ${ }^{[16]}$. This leads to the generation of the 2 second messengers: inositol 1,4,5-trisphosphate $\left(\mathrm{IP}_{3}\right)$; and diacylglycerol (DAG). Both second messengers are believed to be involved in the generation of the physiological response to oxytocin ${ }^{[17,18]}$, although their relative contributions to the overall effect are unknown. There is substantial evidence in published reports that cytoplasmic $\mathrm{Ca}^{2+}$ concentration $\left(\left[\mathrm{Ca}^{2+}\right]_{\mathrm{i}}\right)$ determines myometrial contraction and is involved in stimulatory action of oxytocin ${ }^{[19]}$. However important, the $\mathrm{IP}_{3}$-mediated $\left[\mathrm{Ca}^{2+}\right]_{\mathrm{i}}$ release does not appear to be the whole story. Disabling the sarcoendoplasmic reticulum (SR) using a specific SR $\mathrm{Ca}^{2+} \mathrm{ATP}$-ase inhibitor, thapsigargin, does not abolish the oxytocin-induced increase in the amplitude of myometrial contractions (Figure 1). An example of changes in spontaneous contractions of an isolated strip of human myometrium in response to oxytocin application is given in Figure 1A. At least three distinct components can be discerned in the effect of oxytocin on human uterine smooth muscle: (1) increase in frequency of contractions; (2) initial transient increase in the base tone (incomplete relaxation); and (3) long-lasting increase in the amplitude and duration of phasic contractions. Even prolonged treatment (more than $1 \mathrm{~h}$ ) of the myometrium with thapsigargin to disable the SR abolishes only the first 2 components of the oxytocin effect and does not change the third. That is, the oxytocin-induced increase in frequency of contractions and the transient rise in base tone are eliminated, but not the oxytocin-induced potentiation of force (Figure 1B). These data indicate that, in addition to the $\mathrm{IP}_{3}$-mediated $\mathrm{Ca}^{2+}$ release, other processes might be involved in oxytocin-induced modulation of myometrial contractility. We will discuss these after reviewing the oxytocin-induced $\left[\mathrm{Ca}^{2+}\right]_{\mathrm{i}}$ signaling.

\section{Oxytocin-mediated $\mathrm{Ca}^{2+}$ release and excitation- contraction coupling in myometrium}

Myometrium is a phasic smooth muscle with an intrinsic ability to generate spontaneous contractions. It is generally accepted that myometrial contractions are myogenic, that is, neural or hormonal stimuli are not required for the contractions to occur, but do modulate them. Slow depolarization of the myometrium preceding the discharge of action potentials is attributed to the activity of certain cells, considered pacemaker cells. In some types of visceral smooth muscle, for example, gastrointestinal ${ }^{[20]}$, urogenital ${ }^{[21]}$ and vascular ${ }^{[22]}$, a

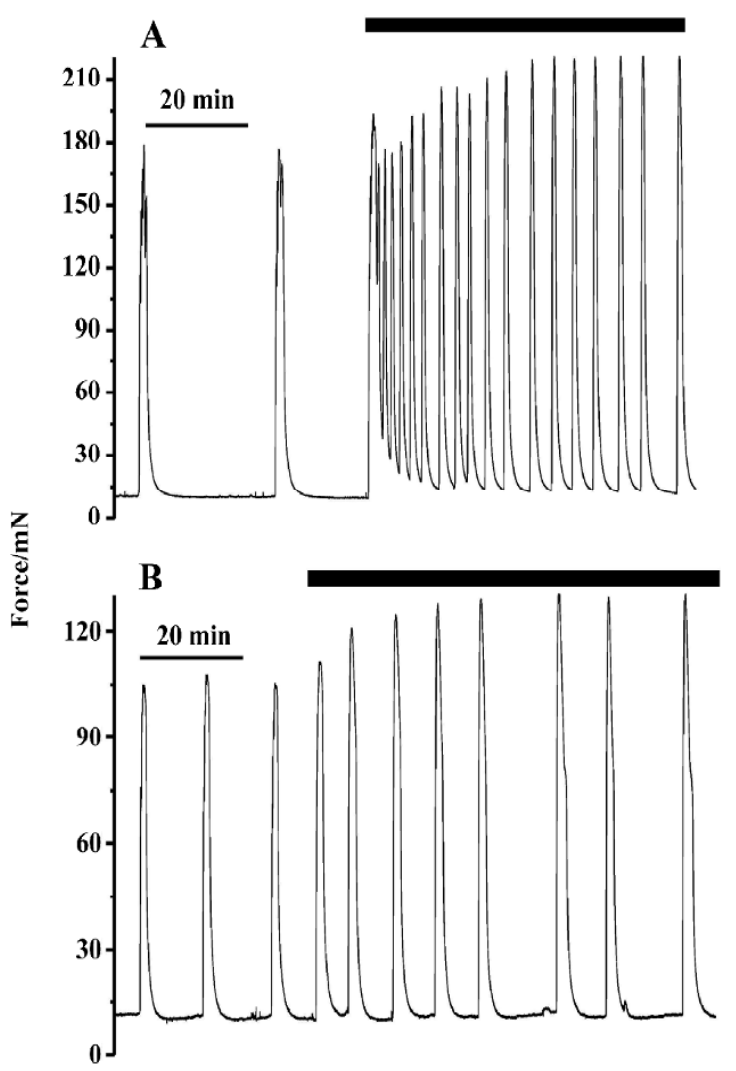

Figure 1. Effect of oxytocin on spontaneous contractions of human myometrial strips. Addition of $10 \mathrm{nmol} / \mathrm{L}$ oxytocin to the organ bath is indicated by solid bars above traces. (A) control; (B) after 70 min pre-treatment with thapsigargin to disable the SR. Thapsigargin abolished transient rise in the baseline seen in $\mathrm{A}$ at the beginning of oxytocin application and almost eliminated increase in frequency of contractions.

specialized type of cell called interstitial cells of Cajal (ICC) had been found. In some, but not all tissues, these cells constitute a pacemaking mechanism. Our recent study has identified the ICC-like cells in human and rat myometrium ${ }^{[23]}$. It is therefore a plausible scenario that the multiple components in the effect of oxytocin are due to its action on different cell types within the myometrium. The ICC-like cells might mediate changes in frequency, whereas smooth muscle cells are responsible for the increase in amplitude of contractions. More research into this area is needed to make informed conclusions regarding the role of ICC-like cells in the regulation of myometrial contractility.

Several research groups have investigated oxytocin-induced $\left[\mathrm{Ca}^{2+}\right]_{\mathrm{i}}$ signaling using $\mathrm{Ca}^{2+}$ sensitive dyes in primary cultures of rat ${ }^{[24]}$, human myometrial cells ${ }^{[25]}$ and in a cell line derived from pregnant human myometrium ${ }^{[26,27]}$. In all types of cells studied, these transients persisted in $\mathrm{Ca}^{2+}$-free solu- 
tion and were abolished by thapsigargin, indicating their SR origin. In the absence of extracellular $\mathrm{Ca}^{2+}$, even a brief application of oxytocin to primary human myometrial cells caused a full-sized $\left[\mathrm{Ca}^{2+}\right]_{\mathrm{i}}$ transient, but subsequent applications of agonist were ineffective. Desensitization of the oxytocin receptors can be ruled out because readmission of extracellular $\mathrm{Ca}^{2+}$ led to restoration of the oxytocin-induced $\left[\mathrm{Ca}^{2+}\right]_{\mathrm{i}}$ transients with $2 \mathrm{~min}^{[25]}$. These data might suggest that oxytocin completely emptied the store during the first application and there was nothing left for the subsequent applications. Alternatively, the ineffectiveness of multiple applications of oxytocin might reflect a steep dependence of the $\mathrm{IP}_{3}$-induced $\mathrm{Ca}^{2+}$ release on intraluminal $\mathrm{Ca}^{2+}$ concentration $\left(\left[\mathrm{Ca}^{2+}\right]_{\mathrm{L}}\right)$, so that even a moderate decrease in $\left[\mathrm{Ca}^{2+}\right]_{\mathrm{L}}$ will render the $\mathrm{IP}_{3}$ receptors insensitive to $\mathrm{IP}_{3}{ }^{[28]}$. The extent to which a single application of oxytocin depletes the SR is important because store depletion can trigger capacitative $\mathrm{Ca}^{2+}$ entry through store-operated $\mathrm{Ca}^{2+}$ channels on the surface membrane. Several isoforms of TrpC have been identified in the myometrium ${ }^{[29]}$. Whether or not these channels contribute to the excitation-contraction coupling should depend on the amount of $\mathrm{Ca}^{2+}$ displaced from the SR by oxytocin via $\mathrm{IP}_{3}$-mediated $\mathrm{Ca}^{2+}$ release. It is difficult to estimate the extent of the SR depletion without actually measuring intraluminal $\mathrm{Ca}^{2+}$. In recent years, new powerful experimental approaches to direct measurement of $\left[\mathrm{Ca}^{2+}\right]_{\mathrm{L}}$ have been developed. These include $\mathrm{Ca}^{2+}$-sensitive fluorescent and luminescent proteins targeted to the SR and low-affinity $\mathrm{Ca}^{2+}$-sensitive dyes selectively loaded into the SR. A detailed discussion of these methods, their advantages and pitfalls has been published ${ }^{[30]}$. In our study, we combined the low-affinity $\mathrm{Ca}^{2+}$ indicator Mag-Fluo-4 with a high-affinity dye Fura-2 to measure $\left[\mathrm{Ca}^{2+}\right]_{\mathrm{L}}$ and $\left[\mathrm{Ca}^{2+}\right]_{\mathrm{i}}$ simultaneously in freshly isolated uterine myocytes ${ }^{[31]}$. The data obtained in our experiments on rat myometrial cells suggest a very steep dependence between the SR filling state and the effectiveness of the $\mathrm{IP}_{3}$-mediated $\mathrm{Ca}^{2+}$ release in intact cells ${ }^{[32]}$. That is, even a moderate depletion of the $\left[\mathrm{Ca}^{2+}\right]_{\mathrm{L}}$ (approximately $20 \%$ of its normal content) abolishes the agonist-induced cytoplasmic $\mathrm{Ca}^{2+}$ transients. Thapsigargin treatment causes slow decrease in the luminal $\mathrm{Ca}^{2+}$ due to unbalanced passive $\mathrm{Ca}^{2+}$ leak and abolishes the agonist-induced $\left[\mathrm{Ca}^{2+}\right]_{\mathrm{i}}$ transients ${ }^{[32]}$. An example of simultaneous recording of $\left[\mathrm{Ca}^{2+}\right]_{\mathrm{L}}$ and $\left[\mathrm{Ca}^{2+}\right]$ ${ }_{i}$ is given in Figure 2. A measurable decrease in $\left[\mathrm{Ca}^{2+}\right]_{\mathrm{L}}$ and a transient rise in $\left[\mathrm{Ca}^{2+}\right]_{\mathrm{i}}$ is seen after application of oxytocin in the absence of extracellular $\mathrm{Ca}^{2+}$ (Figure 2A). After transient increase, the cytoplasmic $\mathrm{Ca}^{2+}$ returns to its resting level in the presence of oxytocin. The intraluminal $\mathrm{Ca}^{2+}$ decreases at the beginning of the oxytocin application and remains at a
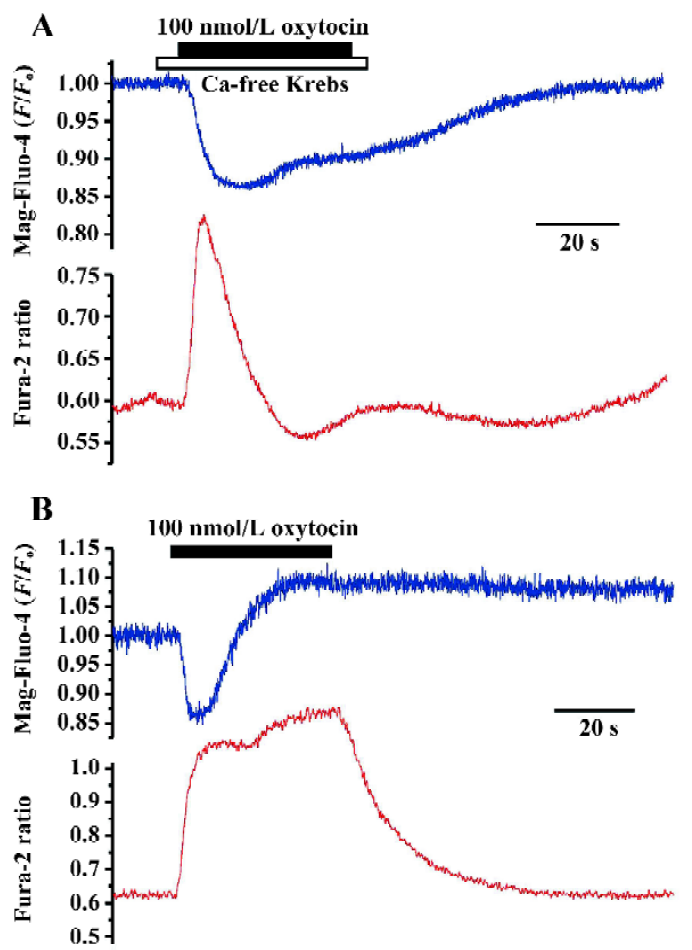

Figure 2. Changes in luminal (blue traces) and cytoplasmic (red traces) $\mathrm{Ca}^{2+}$ concentrations produced by oxytocin in isolated rat uterine myocytes double-labeled with Mag-Fluo-4 and Fura-2; (A) in $\mathrm{Ca}^{2+}$-free extracellular solution (open bar), (B) in normal Krebs solution. Addition of $100 \mathrm{nmol} / \mathrm{L}$ oxytocin is indicated by solid bars.

decreased level for as long as the cell is exposed to $\mathrm{Ca}^{2+}$-free extracellular solution, even though the oxytocin has been washed out. After readmission of extracellular $\mathrm{Ca}^{2+}$, the $\left[\mathrm{Ca}^{2+}\right]$ ${ }_{\mathrm{L}}$ returns to its initial level within 2-3 min. However, under physiological conditions (ie, in the presence of extracellular $\mathrm{Ca}^{2+}$ ), a completely different result is obtained: the cytoplasmic $\mathrm{Ca}^{2+}$ rises to a somewhat higher level and, more importantly, remains at this high level for long period of time (Figure 2B). The dynamics of luminal $\mathrm{Ca}^{2+}$ is also different under these conditions. Thus, only a transient fall in the $\left[\mathrm{Ca}^{2+}\right]_{\mathrm{L}}$ level occurs at the beginning of oxytocin application, immediately followed by the increase above resting level, suggesting uptake of $\mathrm{Ca}^{2+}$ into the SR. These data indicate that, under physiological conditions, oxytocin triggers a complex $\left[\mathrm{Ca}^{2+}\right]_{\mathrm{i}}$ response consisting of initial $\mathrm{Ca}^{2+}$ release from the SR followed by $\mathrm{Ca}^{2+}$ entry from outside. This oxytocininduced $\mathrm{Ca}^{2+}$ entry leads to sustained elevation in $\left[\mathrm{Ca}^{2+}\right]_{\mathrm{i}}$ that underlies increased uptake of $\mathrm{Ca}^{2+}$ into the SR. The process is unlikely to be triggered by store depletion, as there is no persistent decrease in $\left[\mathrm{Ca}^{2+}\right]_{\mathrm{L}}$. However, the possibility of the TrpC involvement in the oxytocin-induced 
$\left[\mathrm{Ca}^{2+}\right]_{\mathrm{i}}$ signaling still exists. In a recent study, a direct activation of extracellular $\mathrm{Ca}^{2+}$ entry through TrpC by 1-oleoyl2acetyl-sn-glycerol, a membrane-permeant analog of DAG, was found in both primary uterine myocytes and immortalized myometrial cell line derived from pregnant uterus ${ }^{[18]}$.

It has to be borne in mind that, under physiological conditions, the excitation-contraction cycle occurs spontaneously and the SR $\mathrm{Ca}^{2+}$ release and entry induced by continuous oxytocin application will be imposed on the action potential triggered $\left[\mathrm{Ca}^{2+}\right]_{\mathrm{i}}$ transients. Therefore, the phasic effect of the elevated $\mathrm{IP}_{3}$ level has to be viewed through the prism of the excitation-contraction coupling process. A generally accepted mechanism of the myometrial excitation-contraction coupling is that the action potential-induced rise in $\left[\mathrm{Ca}^{2+}\right]_{\mathrm{i}}$ triggers acto-myosin interaction by $\mathrm{Ca}^{2+}$-calmodulinmediated phosphorylation of the regulatory myosin light chains ${ }^{[33]}$. In the presence of oxytocin, or indeed any $\mathrm{IP}_{3}$ producing agent, the amplitude of the action potential-induced $\left[\mathrm{Ca}^{2+}\right]_{\mathrm{i}}$ transients can, in principle, be potentiated by sustained elevation of $\mathrm{IP}_{3}$. The possibility of such potentiation stems from the bell-shaped $\mathrm{Ca}^{2+}$ dependence of the $\mathrm{IP}_{3}$ receptor sensitivity to $\mathrm{IP}_{3}{ }^{[34]}$. That is, at sub-maximal levels of $\mathrm{IP}_{3}$, the rise in $\left[\mathrm{Ca}^{2+}\right]_{\mathrm{i}}$ produced by the inward $\mathrm{Ca}^{2+}$ current will augment the $\mathrm{IP}_{3}$-mediated $\mathrm{SR} \mathrm{Ca}^{2+}$ release at 200-300 $\mathrm{nmol} / \mathrm{L}\left[\mathrm{Ca}^{2+}\right]_{\mathrm{i}}$ and diminish it when $\left[\mathrm{Ca}^{2+}\right]_{\mathrm{i}}$ exceeds $500-600$ $\mathrm{nmol} / \mathrm{L}$. The mechanism of oxytocin-induced changes in the frequency of contractions has not been elucidated yet. As the frequency effect of oxytocin is abolished by thapsigargin, it must be related to the $\mathrm{IP}_{3}$-mediated $\mathrm{Ca}^{2+}$ release from the $\mathrm{SR}$ and concomitant activation of $\mathrm{Ca}^{2+}$ activated channels ${ }^{[35,36]}$. Clearly, the mechanism(s) of oxytocin-induced increase in frequency of uterine contractions can only be addressed once we understand the mechanism(s) of myometrial autorhythmicity.

\section{Oxytocin-mediated $\mathrm{Ca}^{2+}$ sensitization}

Almost half a century of experimental research on many types of smooth muscle provided convincing evidence that contractility of smooth muscle is regulated not only by electromechanical coupling but also by membrane potentialindependent, pharmacomechanical coupling ${ }^{[37]}$. Many agonists induce sensitization of contractile apparatus to $\mathrm{Ca}^{2+}$ by inhibiting myosin phosphatase and decreasing the rate of myosin regulatory chain dephosphorylation. This prolongs myosin light chain phosphorylation, leading to enhanced tension without influencing $\left[\mathrm{Ca}^{2+}\right]_{i}^{[38,39]}$. The contractile apparatus can therefore produce more force at given $\left[\mathrm{Ca}^{2+}\right]_{\mathrm{i}}$. This also implies that the rate of relaxation will be decreased in the presence of agonist. Indeed, oxytocin decreases the rate of relaxation in human myometrium ${ }^{[40]}$. Figure $3 \mathrm{~A}$ shows superimposed traces of force (upper traces) and its first derivative (lower traces) in control (blue traces) and in the presence of oxytocin (red traces). It is clear that oxytocin not only increases the amplitude and duration of contraction but also decreases the peak rate of relaxation. Similar results were obtained after thapsigargin treatment (Figure 3B) indicating $\mathrm{SR} \mathrm{Ca}^{2+}$ release is not involved in this process. Simultaneous measurements of $\left[\mathrm{Ca}^{2+}\right]_{i}$ and force from human myometrium revealed that oxytocin applied to strips depolarized by $\mathrm{KCl}$ could increase force without affecting $\left[\mathrm{Ca}^{2+}\right]_{i}^{[41]}$. In our experiments, oxytocin increased force without affecting peak amplitude of $\left[\mathrm{Ca}^{2+}\right]_{\mathrm{i}}$ transients $^{[40]}$. Molecular mechanisms involved in $\mathrm{Ca}^{2+}$ sensitization are currently being investigated in several laboratories. In many tissue types, RhoA, a monomeric G-protein, can mediate $\mathrm{Ca}^{2+}$ sensitisation $^{[42]}$. Activation occurs on stimulation of receptors coupled to $\mathrm{G} \alpha_{12,13} ; \mathrm{G} \alpha_{\mathrm{q}}$ or $\mathrm{G} \alpha_{\mathrm{i}}^{[43]}$, which convert inactive
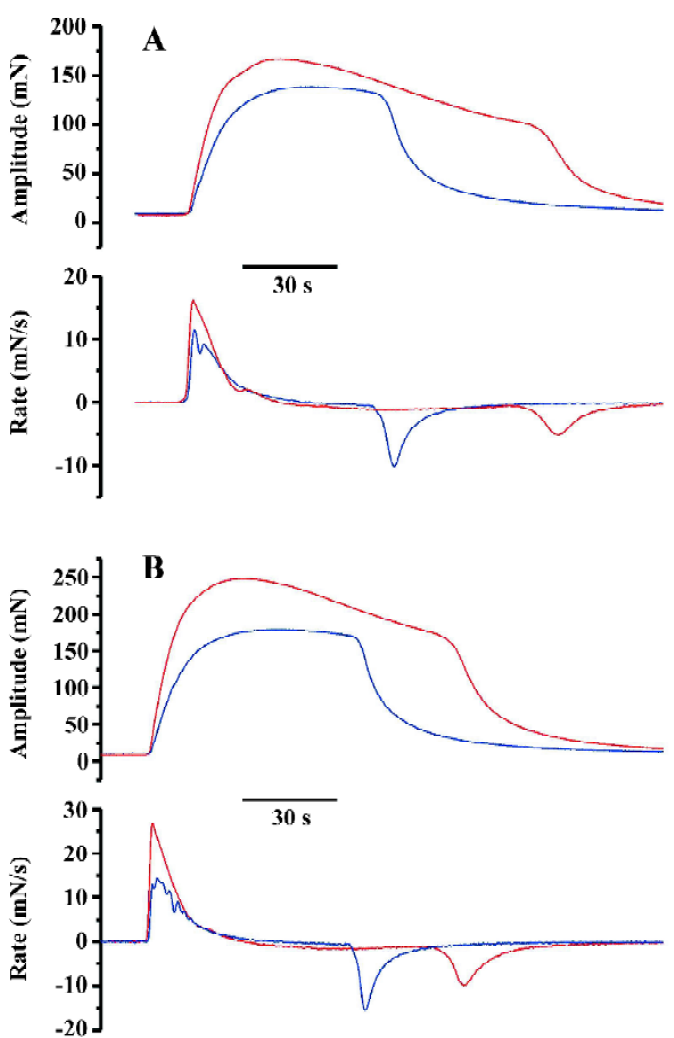

Figure 3. Oxytocin increases amplitude and rate of rise of contraction but decreases the rate of relaxation in human myometrium. Selected isometric contractions (upper traces) and their first derivative (lower traces) obtained in the absence (blue traces) and in the presence (red traces) of $100 \mathrm{nmol} / \mathrm{L}$ oxytocin are superimposed and aligned to the onset of contraction. (A) control; (B) after $65 \mathrm{~min}$ treatment with thapsigargin. 


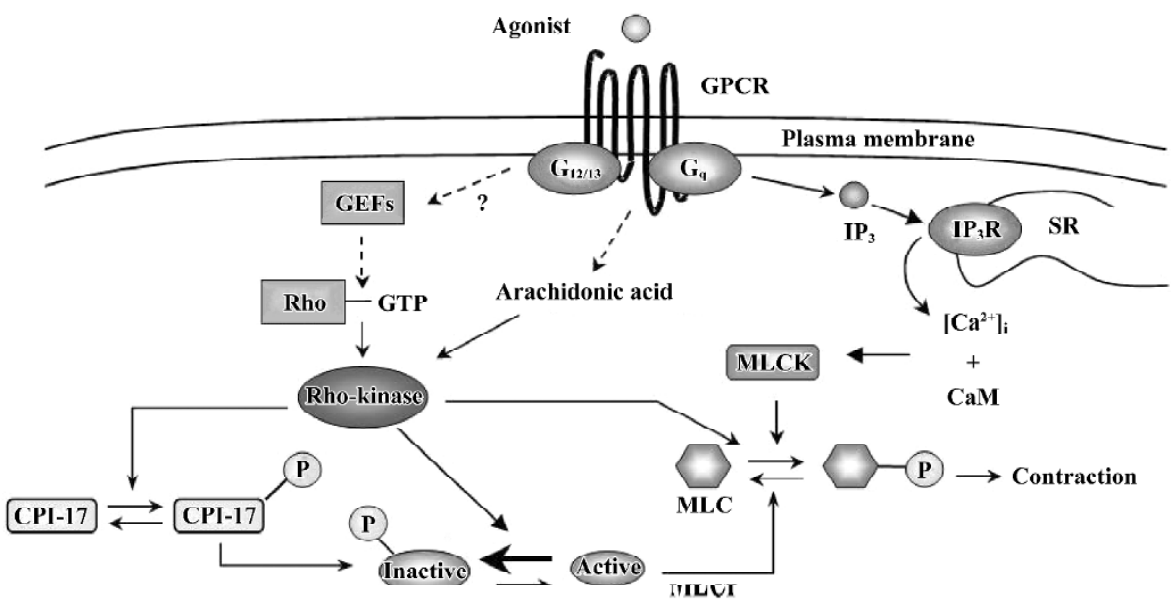

Figure 4. Diagramatic representation of multiple mechanisms involved in the oxytocin-induced modulation of myometrial contractility (see text for details). CaM, calmodulin; $\mathrm{G}_{9}$, and $\mathrm{G}_{12 / 13}$ guanine nucleotide binding proteins; GEFs, guanine nucleotide exchange factors; GPCR, G-protein coupled receptor; $\mathrm{IP}_{3} \mathrm{R}$, inositol 1,4, 5-trisphosphate; MLC, myosin light chain; MLCK, myosin light chain kinase; MLCP, myosin light chain phosphatase; $\mathrm{P}$, phosphate residue on phosphorylated MLC, MLCP and CPI-17.
RhoA.GDP to active RhoA.GTP through the action of guanine nucleotide exchange factors. RhoA·GTP acts through a serine/threonine kinase (Rho kinase) that phosphorylates the regulatory subunit of MLCP, thereby inhibiting phosphatase activity. It has been shown that upregulation of RhoA and Rho kinase occurs in human myometrium during pregnancy ${ }^{[44]}$. It has also been demonstrated that inhibition of Rho kinase activity by Y-27632 reduces tension but not $\left[\mathrm{Ca}^{2+}\right]_{\mathrm{i}}$ during spontaneous and oxytocin-induced contractions in human myometrium ${ }^{[41]}$. Thus, Rho kinase mediates (at least in part) oxytocin-induced increase in myometrial contractility. This mechanism is summarized in Figure 4. It remains to be determined whether Rho A is the activator of Rho kinase in myometrium. The oxytocin receptor has not been shown to couple to $\mathrm{G} \alpha_{12,13}$ although activation of Rho A could occur through $\mathrm{G \alpha}_{\mathrm{q}}$. The situation becomes even more complicated because arachidonic acid can also activate Rho kinase (Figure 4) and might mediate Rho kinasedependent $\mathrm{Ca}^{2+}$ sensitization ${ }^{[45]}$.

In addition to Rho kinase, protein kinase $\mathrm{C}$ modulates myosin light chain phosphatase activity either by direct phosphorylation or a smooth-muscle specific inhibitor called CPI-17. Activation (phosphorylation) of CPI-17 inhibits the catalytic subunit of MLCP leading to increased light chain phosphorylation and enhanced contraction at a given $\left[\mathrm{Ca}^{2+}\right]_{\mathrm{i}}^{[46]}$. As Rho kinase ${ }^{[47]}$ and arachidonic acid ${ }^{[45]}$ also activate CPI-17, this suggests that these pathways could converge on CPI-17 to increase the $\left[\mathrm{Ca}^{2+}\right]_{\mathrm{i}}$ sensitivity of contractile apparatus.

It appears that $\mathrm{Ca}^{2+}$ sensitization is the longest lasting effect of oxytocin on human myometrium. In fact, contractions of potentiated amplitude can be recorded for many hours, whereas increase in the base tone (incomplete relaxation) takes place only at the beginning of oxytocin applica- tion and lasts only a short time. Clearly, tonic contraction of the uterus during labor is undesirable as it would lead to foetal distress through decreased blood supply to the foetus. An increase in the amplitude and frequency of phasic contractions will aid successful labor. The data discussed in this review suggest that the tonic contraction seen at the beginning of oxytocin application (see Figure 1) and changes in frequency of contractions are mediated by the $\mathrm{SR} \mathrm{Ca}^{2+}$, and potentiation of contraction amplitude is achieved by sensitization of contractile machinery to $\mathrm{Ca}^{2+}$. This process appears to be the most relevant physiologically and should be concentrated on in the future research.

\section{References}

1 Challis JRG, Lye SJ. Parturition. In: Clarke JR, editor. Oxford reviews of reproductive biology. Oxford: Oxford University Press; 1986. p 61-129.

2 Lye SJ. Evidence for an intrinsic control of myometrial contractile periodicity in sheep during pregnancy. J Reprod Fertil 1992; 96: $337-45$.

3 Dale HH. On the physiological action of ergot. J Physiol 1906; 34: 163-206.

4 Du Vigneaud V, Resller S, Trippett S. The sequense of aminoacids in oxytocin, with a proposal for the structure of oxytocin. J Biol Chem 1953; 205: 949-57.

5 Blair Bell W. The pituitary body. Br Med J 1909; 2: 1609-13.

6 Theobold GW, Robards MF, Suter T. Changes in myometrial sensitivity to oxytocin in man during the last six weeks of pregnancy. J Obstet Gynaecol Br Common 1969; 76: 385-90.

7 Nishimori K, Young LJ, Guo Q, Wang Z, Insel TR, Matzuk MM. Oxytocin is required for nursing but is not essential for parturition or reproductive behavior. Proc Natl Acad Sci USA 1996; 93: 11699-704.

8 Young LJ, Wang Z, Insel TR. Neuroendocrine basis of monogamy. Trends Neuroci 1998; 21: 71-5.

9 Blanks AM, Thornton S. The role of oxytocin in parturition. BJOG 2003; 110: 46-51.

10 Gimpl G, Fahrenholz F. The oxytocin receptor system: structure, 
function and regulation. Physiol Rev 2001; 81: 629-83.

11 Lopez Bernal A. Mechanisms of labour - biochemical aspects. BJOG 2003; 110 Suppl 20: 39-45.

12 Mitchell BF, Schmid B. Oxytocin and its receptor in the process of parturition. J Soc Gynecol Investig 2001; 8: 122-33.

13 Zingg HH, Laporte SA. The oxytocin receptor. Trends Endocrinol Metab 2003; 14: 222-7.

14 French/Australian Atosiban Investigators Group. Treatment of preterm labour with the oxytocin antagonist atosiban: a doubleblind, randomized controlled comparison with salbutamol. Eur J Obstet Gynecol Reprod Biol 2001; 98: 177-85.

15 Worldwide Atosiban vs $\beta$-agonists Study Group. Effectiveness and safety of the oxytocin antagonist atosiban versus $\beta$-adrenergic agonists in the treatment of preterm labour. The Worldwide Atosiban vs $\beta$-agonists Study Group. BJOG 2001; 108: 133-142.

$16 \mathrm{Ku} \mathrm{CY}$, Qian A, Wen Y, Anwer K, Sanborn BM. Oxytocin stimulates myometrial guanosine triphosphatase and phospholipase-C activities via coupling to $G$ alpha q/11. Endocrinology 1995; 136: $1509-15$.

17 Sanborn BM, Ku CY, Shlykov S, Babich L. Molecular signaling through G-protein-coupled receptors and the control of intracellular calcium in myometrium. J Soc Gynecol Investig 2005; 12: 479-87.

18 Shlykov SG, Sanborn BM. Stimulation of intracellular $\mathrm{Ca}^{2+}$ oscillations by diacylglycerol in human myometrial cells. Cell Calcium 2004; 36: 157-64.

19 Wray S, Jones K, Kupittayanant S, Li Y, Matthew A, MonirBishty E, et al. Calcium signaling and uterine contractility. J Soc Gynecol Invest 2003; 10: 252-64.

20 Sanders KM. Postjunctional electrical mechanisms of enteric neurotransmission. Gut 2000; 47: 23-25.

21 Sergeant GP, Hollywood MA, McCloskey KD, Thornbury KD, McHale NG. Specialised pacemaking cells in the rabbit urethra. J Physiol (Lond) 2000; 526: 359-66.

22 Harhun MI, Gordienko DV, Povstyan OV, Moss RF, Bolton TB. Function of interstitial cells of Cajal in the rabbit portal vein. Circ Res 2004; 95: 619-26.

23 Duquette RA, Shmygol A, Vaillant C, Mobasheri A, Pope M, Burdyga $\mathrm{T}$, et al. Vimentin-positive, c-KIT-negative interstitial cells in human and rat uterus: a role in pacemaking? Biol Reprod 2005; 72: 276-83.

24 Arnaudeau S, Lepretre N, Mironneau J. Oxytocin mobilizes calcium from a unique heparin-sensitive and thapsigargin-sensitive store in single myometrial cells from pregnant rats. Pflugers Arch 1994; 428: 51-9.

25 Thornton S, Gillespie JI, Greenwell JR, Dunlop W. Mobilization of calcium by the brief application of oxytocin and prostaglandin-E2 in single cultured human myometrial cells. Exp Physiol 1992; 77: 293-305.

26 Burghardt RC, Barhoumi R, Sanborn BM, Andersen J. Oxytocininduced $\mathrm{Ca}^{2+}$ responses in human myometrial cells. Biol Reprod 1999; 60: 777-82.

27 Monga M, Ku CY, Dodge K, Sanborn BM. Oxytocin-stimulated responses in a pregnant human immortalized myometrial cell line. Biol Reprod 1996; 55: 427-32.

28 Missiaen L, De Smedt H, Droogmans G, Casteels R. Luminal $\mathrm{Ca}^{2+}$ controls the activation of the inositol 1,4,5-trisphosphate receptor by cytosolic $\mathrm{Ca}^{2+}$. J Biol Chem 1992; 267: 22961-6.

29 Babich LG, Ku CY, Young HW, Huang H, Blackburn MR, Sanborn $\mathrm{BM}$, et al. Expression of capacitative calcium TrpC proteins in rat myometrium during pregnancy. Biol Reprod 2004; 70: 919-24.

30 Solovyova N,Verkhratsky A. Monitoring of free calcium in the neuronal endoplasmic reticulum: an overview of modern approaches. J Neurosci Methods 2002; 122: 1-12.

31 Shmigol AV, Eisner DA, Wray B. Simultaneous measurements of changes in sarcoplasmic reticulum and cytosolic $\left[\mathrm{Ca}^{2+}\right]$ in rat uterine smooth muscle cells. J Physiol (London) 2001; 531: 707-13.

32 Shmygol A, Wray S. Modulation of agonist-induced $\mathrm{Ca}^{2+}$ release by $\mathrm{SR} \mathrm{Ca}^{2+}$ load: direct SR and cytosolic $\mathrm{Ca}^{2+}$ measurements in rat uterine myocytes. Cell Calcium 2005; 37: 215-23.

33 Wray S, Kupittayanant S, Shmygol A, Smith RD, Burdyga T. The physiological basis of uterine contractility: a short review. Exp Physiol 2001; 86: 239-46.

34 Miyakawa T, Mizushima A, Hirose K, Yamazawa T, Bezprozvanny I, Kurosaki T, et al. $\mathrm{Ca}^{2+}$-sensor region of IP3 receptor controls intracellular $\mathrm{Ca}^{2+}$ signaling. EMBO J 2001; 20: 1674-80.

35 Arnaudeau S, Lepretre N, Mironneau J. Chloride and monovalent ion-selective cation currents activated by oxytocin in pregnant rat myometrial cells. Am J Obstet Gynecol 1994; 171: 491-501.

36 Jones K, Shmygol A, Kupittayanant S, Wray S. Electrophysiological characterization and functional importance of calciumactivated chloride channel in rat uterine myocytes. Pflugers Arch 2004; 448: 36-43.

37 Somlyo AP, Somlyo AV. Signal transduction by G-proteins, Rhokinase and protein phosphatase to smooth muscle and non-muscle myosin II. J Physiol (London) 2000; 522: 177-85.

38 Amano M, Ito M, Kimura K, Fukata Y, Chihara K, Nakano T, et al. Phosphorylation and activation of myosin by Rho-associated kinase (Rho-kinase). J Biol Chem 1996; 271: 20246-9.

39 Kimura K, Ito M, Amano M, Chihara K, Fukata Y, Nakafuku M, et al. Regulation of myosin phosphatase by Rho and Rho-associated kinase (Rho-kinase). Science 1996; 273: 245-8.

40 McKillen K, Thornton S, Taylor CW. Oxytocin increases the $\left[\mathrm{Ca}^{2+}\right]_{\mathrm{i}}$ sensitivity of human myometrium during the falling phase of phasic contractions. Am J Physiol Endocrinol Metab 1999; 276: E345-E351.

41 Kupittayanant S, Burdyga T, Wray S. The effects of inhibiting Rho-associated kinase with Y-27632 on force and intracellular calcium in human myometrium. Pflugers Arch 2001; 443: 112-4.

42 Yamamori B, Ito M, Feng JH, Nakano T, Okawa K, Iwamatsu A, et al. Mechanism for regulation of smooth muscle contraction by the small G protein Rho. Circulation 1996; 94: 1662.

43 Katoh H, Aoki J, Yamaguchi Y, Kitano Y, Ichikawa A, Negishi M. Constitutively active G alpha(12), G alpha(13), and G alpha (q) induce rho-dependent neurite retraction through different signaling pathways. J Biol Chem 1998; 273: 28700-7.

44 Moore F, Da Silva C, Wilde JI, Smarason A, Watson SP, Lopez Bernal A. Up-regulation of $\mathrm{p} 21$-and RhoA-activated protein kinases in human pregnant myometrium. Biochem Biophys Res Commun 2000; 269: 322-6.

45 Gong MC, Kinter MT, Somlyo AV, Somlyo AP. Arachidonicacid and diacylglycerol release associated with inhibition of myosin light-chain dephosphorylation in rabbit smooth-muscle. J Physiol (London) 1995; 486: 113-22.

46 Kitazawa T, Eto M, Woodsome TP, Brautigan DL. Agonists trigger $\mathrm{G}$ protein-mediated activation of the CPI-17 inhibitor phosphoprotein of myosin light chain phosphatase to enhance vascular smooth muscle contractility. J Biol Chem 2000; 275: p 9897-900.

47 Eto M, Wong L, Yazawa M, Brautigan DL. Inhibition of myosin phosphatase through CPI-17 phosphorylated by Rho-kinase and protein kinase N. Circulation 2000; 102: 320 . 